\title{
Coding strategies and imagery differences in memory
}

\author{
SHINSUKE HISHITANI \\ Department of Literature, Seinan Gakuin University, Sawara-ku, Fukuoka 814
}

\begin{abstract}
Both sentence-generation and imagery-formation are effective coding strategies in learning and memory of verbal materials. However, the problem of which is the more effective, or whether the efficiency of both strategies is the same or not, has not been decided yet. For this problem two theoretical standpoints are possible. One is the semantic elaboration model, and the other is the imagery elaboration model. In previous studies, both models have empirical supports. Here, this problem was examined by introducing the variable of imagery differences. Prior to the experiments, the VVIQ was administered to subjects (160 undergraduates) in order to assess their imagery ability. The main findings were as follows: Imagery-formation is more effective than sentence-generation in memory of verbal materials, the effects of imagery-formation continues longer in good imagers than in poor imagers, and good imagers are apt to voluntarily use imagery in processing input information. These results supported the imagery elaboration model, and this model was refined in order to explain the effects of imagery differences and coding strategies on memory.
\end{abstract}

Key words: verbal memory, semantic elaboration model, imagery elaboration model, coding strategies, sentence-generation, imagery-formation, imagery differences.

It is well known that both sentence-generation and imagery-formation are effective coding strategies in learning and memory of verbal materials. However, the problem of which strategy is the more effective, or whether the efficiency of both is the same or not, has not yet been decided. For this problem, two theoretical standpoints are possible, according to the mode of thought about the memory system.

One standpoint is represented by the semantic elaboration model (Anderson \& Bower, 1973; Bower, 1970). According to this model the effect of imagery on memory performance is regarded as a by-product in imagery-formation. In this model, it is hypothesized that both sentences and imagery have the same function of linking input items, and that both of them form elaborated semantic representations or networks. Therefore, there should be no difference in memory performance between the two coding strategies of forming sentences and imagery.

The other standpoint is represented by the imagery elaboration model (Kieras,
1978). In this model, assumed imagery itself takes a direct functional role in memory, and information is stored in a semantic network in the process of sentence-generation, just as in the semantic elaboration model. However, it is supposed that in imagery-formation, input information is encoded in perceptual networks representing perceptual attributes and relationships of imagery in addition to the semantic network. Therefore, performance will be better in imagery coding than in sentencegeneration. In previous studies which compared performance with sentence and imagery codings, both models have empirical supports (e.g., Anderson \& Bower, 1973; Bower, 1972; Milgram, 1967; Mueller \& Jablonski, 1970; Reese, 1965). In this paper, the problem is examined by introducing the variable of imagery difference.

The previous studies which examined the effect of imagery ability on memory show that the memory performance of good imagers is higher than that of poor imagers in the case of imagery coding (c.g., Hishitani, 1982, 1985; Mckelvie \& 
Demers, 1979). According to the semantic elaboration model, imagery is only an epiphenomenon, and the difference between good and poor imagers is reduced to differences in ability to elaborate input information semantically. Consequently, there should be no difference in performance between imagery and sentence encoding strategies regardless of the imagery ability, but the performance level of poor imagers should be lower than that of good ones for both coding strategies.

On the other hand, according to the imagery elaboration model, it is predicted that performance will be higher in imagery coding than in sentence-generation for both good and poor imagers. It may be difficult, however, to find a clear difference in good imagers' performance between two coding conditions, because good imagers are apt to use imagery in processing input information (Kosslyn \& Jolicoeur, 1980; Paivio, 1971; Richardson, 1977a, 1977b). That is, good imagers may construct imageries for input items even under the sentence-generation instruction. If so, their performance will be approximately the same for both coding instructions. However, such a tendency in poor imagers is not so probable, and clear differences are predicted between two coding instructions. Consequently, the results may change according to the imagery ability, even if imagery coding is overall more effective than sentence-generation as the imagery elaboration model predicts. As previously stated, therefore, the variable of imagery ability is introduced into the present study.

\section{Experiment 1}

\section{Method}

Subjects. Two groups of subjects took part in the experiment. Sixty-six college students in the first group performed the two types of encoding tasks, sentence-generation first and imagery-formation second, while 94 students in the second group performed imagery first and sentence second.

Materials. Ten triplets of concrete nouns with an integrated imagery value of less than 2.9 were selected from Hishitani (1980); five of these triplets were used for sentence-generation and the other five for imagery-formation. Low imagery triplets were used to suppress voluntary imagery coding as much as possible.

Procedure. First, the VVIQ (Marks, 1973) was administered to subjects in order to measure their imagery ability. Then the subjects constructed sentences and imageries for the triplets by relating three nouns with each other. The triplets were presented orally one at a time to the entire group; coding time was $90 \mathrm{~s}$. The subjects were instructed that since the purpose of this experiment was to examine the relation between imagery ability and the time of sentence-generation or the time of imagery-formation, they had to write down the time of completion of sentence-generation or imagery-formation on the response sheet. The experimenter announced the lapse of time every $10 \mathrm{~s}$. This instruction was used to make the subjects concentrate on the coding task. In order to avoid a ceiling effect, there was a time interval of $750 \mathrm{~s}$ after completion of the task, then subjects were asked to perform an unexpected free recall for $300 \mathrm{~s}$.

\section{Results and Discussion}

The 10 lowest scorers and the 10 highest scorers of the VVIQ were selected from each group (20 good imagers and 20 poor ones, 40 subjects in all), and the number of correctly recalled items was analyzed. The results are shown in Table 1 and Fig. 1. The main effect of imagery ability approached the level of significance. This coincides with the results of previous studies, such as Hishitani (1982, 1985), and Mckelvie and Demers (1979). The main effect of coding strategies was significant. This supports the imagery elaboration model, which predicts that imagery should 
Table 1

ANOVA table of A (order of coding strategies) $\times \mathrm{B}$ (imagery ability) $\times \mathrm{C}$ (coding instruction) ${ }^{\mathfrak{a})}$

\begin{tabular}{|c|c|c|c|c|c|}
\hline SOURGE & SS & $d f$ & $M S$ & $F$ & $p$ \\
\hline Between subjects & 615.799 & 39 & & & \\
\hline A & 4.050 & 1 & 4.050 & 0.261 & 0.617 \\
\hline B & 48.049 & 1 & 48.049 & 3.108 & 0.082 \\
\hline$A * B$ & 7.199 & 1 & 7.199 & 0.465 & 0.506 \\
\hline Subj w. groups & 556.500 & 36 & 15.458 & & \\
\hline Within subjects & 387.000 & 40 & & & \\
\hline C & 54.449 & 1 & 54.449 & 6.467 & 0.014 \\
\hline $\mathrm{A} * \mathrm{C}$ & 0.199 & 1 & 0.199 & 0.023 & 0.851 \\
\hline $\mathrm{B} * \mathrm{C}$ & 28.800 & 1 & 28.800 & 3.420 & 0.069 \\
\hline $\mathrm{A} * \mathrm{~B} * \mathrm{C}$ & 0.450 & 1 & 0.450 & 0.053 & 0.803 \\
\hline $\mathrm{C} *$ subj w. groups & 303.099 & 36 & 8.419 & & \\
\hline Total & 1002.800 & 79 & & & \\
\hline
\end{tabular}

a) Only $\mathbf{C}$ is a within factor.

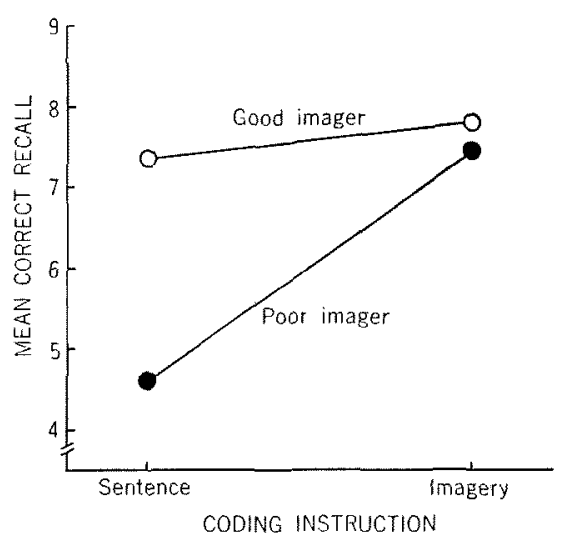

Fig. 1. Mean number of correct recalls of good and poor imagers as a function of coding instruction.

be superior to sentence-generation as a strategy in verbal memory. The effect of coding strategies is particularly clear in poor imagers, and the interaction between the imagery ability and coding strategies approached significance. This is due to the fact that good imagers tend to construct imagery voluntarily in sentence instruction, as described above.

In the imagery elaboration model, it was not clear at which stage of memory the imagery differences appear. Now, if imagery ability means the ability to encode input information into the perceptual net- work, and that perceptual encoding of poor imagers is not as strong as that of good imagers, then it is expected that the memory of poor imagers using imagery coding will decay faster than that of good imagers. In fact, in previous studies it has been established that the recall of good imagers is more robust than that of poor imagers for comparatively long time delays (Hishitani, 1982, 1985). In this experiment, however, in spite of the insertion of a delay of $750 \mathrm{~s}$, there was no difference in the number of recalls between poor imagers and good imagers. This may be because the delay was too short. If the supposition about imagery ability is correct, the number of correct recalls in poor imagers will decay faster than that in good imagers, if we observe recall over a sufficiently long delay time. Besides, if the perceptual coding of poor imagers is insufficient and the efficiency of imagery coding decays rapidly, the amount of decay in the imagery condition may be greater than that of the sentence condition. In Experiment 2, this problem was examined.

\section{Experiment 2}

All students of the second group and 21 
Table 2

ANOVA table of A (imagery ability) $\times \mathrm{B}$ (delay time) $\times \mathrm{C}$ (coding instruction) ${ }^{n}$ )

\begin{tabular}{|c|c|c|c|c|c|}
\hline SOURCE & $S S$ & $d f$ & $M S$ & $F$ & $p$ \\
\hline Between subjects & 893.341 & 29 & & & \\
\hline A & 49.408 & 1 & 49.408 & 1.639 & 0.208 \\
\hline Subj w. groups & 843.933 & 28 & 30.140 & & \\
\hline Within subjects & 740.250 & 90 & & & \\
\hline $\mathrm{B}$ & 316.875 & 1 & 316.875 & 99.691 & 0.000 \\
\hline $\mathrm{A} * \mathrm{~B}$ & 1.875 & 1 & 1.875 & 0.589 & 0.545 \\
\hline$B *$ subj w. groups & 89.000 & 28 & 3.178 & & \\
\hline C & 25.208 & 1 & 25.208 & 3.824 & 0.057 \\
\hline $\mathrm{A} * \mathrm{C}$ & 8.008 & 1 & 8.008 & 1.215 & 0.279 \\
\hline $\mathrm{C} *$ subj w. groups & 184.533 & 28 & 6.590 & & \\
\hline $\mathrm{B} * \mathrm{C}$ & 29.008 & I & 29.008 & 11.116 & 0.002 \\
\hline $\mathrm{A} * \mathrm{~B} * \mathrm{C}$ & 12.675 & 1 & 12.675 & 4.857 & 0.033 \\
\hline $\mathrm{BC} * \operatorname{subj} w$. groups & 73.066 & 28 & 2.609 & & \\
\hline Total & 1633.591 & 119 & & & \\
\hline
\end{tabular}

students of the first group in Experiment 1 were not able to participate Experiment 2 , because they had to attend a lecture when Experiment 2 was carried out. Hence, only 45 students of the first group, which performed two types of encodings in the order of sentence and imagery, were asked to recall for the second time, one week after Experiment 1. Ideally, the same experiment should have been done with the subjects in the second group. However, in Experiment 1, the discrepancy between the two groups was only the order of encoding instruction and its main effect and interaction with other factors were not significant at all. Therefore, it has little effect on the conclusion, if the data for only the first group are examined.

\section{Method}

The subjects were 45 college students of the first group in Experiment 1. They recalled unexpectedly for the second time for $200 \mathrm{~s}$, one week after the first recall.

\section{Results and Discussion}

One-third of the subjects with the highest VVIQ scores and one-third with the lowest VVIQ scores (fifteen persons each) were selected as poor and good imagers, respectively, and the second recall data were compared with the first recall data which were obtained in Experiment 1. The results are shown in Table 2 , and Figs. 2, 3, and 4. The number of recalls and the recall patterns closely resembled those in Fig. I (see Fig. 4). Therefore, the conclusions will not be affected much, even if we use data from the first group only. The most interesting aspect of this supplementary experiment is the poor imagers' decay pattern of the number of recalls as a function of delay time; in Fig. 2 , a significant interaction effect was found only in the right panel $(F(1,56)=4.199$, $p<.05$ ), and in Fig. 3, interaction effect was significant only on the left panel $(F(1,28)=15.337, p<.01)$. These results supported the expectation mentioned in the discussion of Experiment 1.

To explain the results in Figs. 2 and 3 comprehensively, the following hypotheses were constructed. Using these hypotheses, the number of recalls were estimated, and these estimations were compared with the actual recalls.

1) Semantic and perceptual encodings in memory decay with time.

2) Good imagers perform perceptual coding, even if they were given sentence in- 
struction, and its effect continues for a long time. Its efficiency is the same as it is in imagery instruction (from the left panel of Fig. 2 and the right panel of Fig. 3).

3) Poor imagers perform perceptual coding only in the imagery instruction, but the effect diminishes rapidly (from the right panel of Fig. 2 and the left panel of Fig. 3).

4) The rate of decay for the combined effects of semantic and perceptual codings in good imagers is equal to that for semantic coding in poor imagers (from the left panel of Fig. 2). In other words, the decay rate for perceptual coding in good

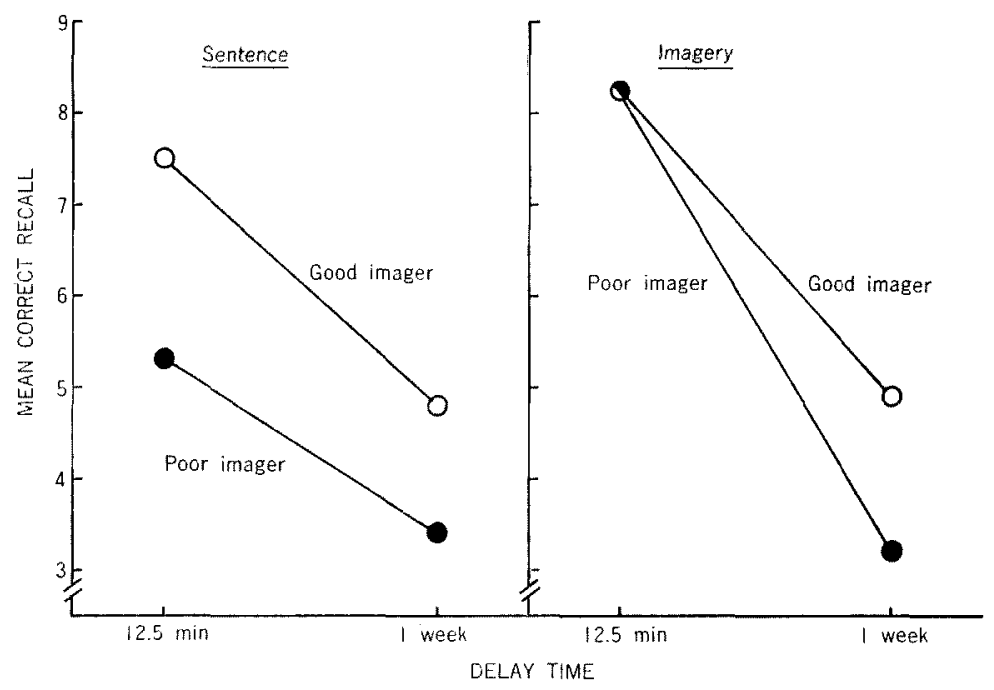

Fig. 2. Mean number of correct recalls of good and poor imagers in sentencegeneration and imagery-formation as a function of delay time.

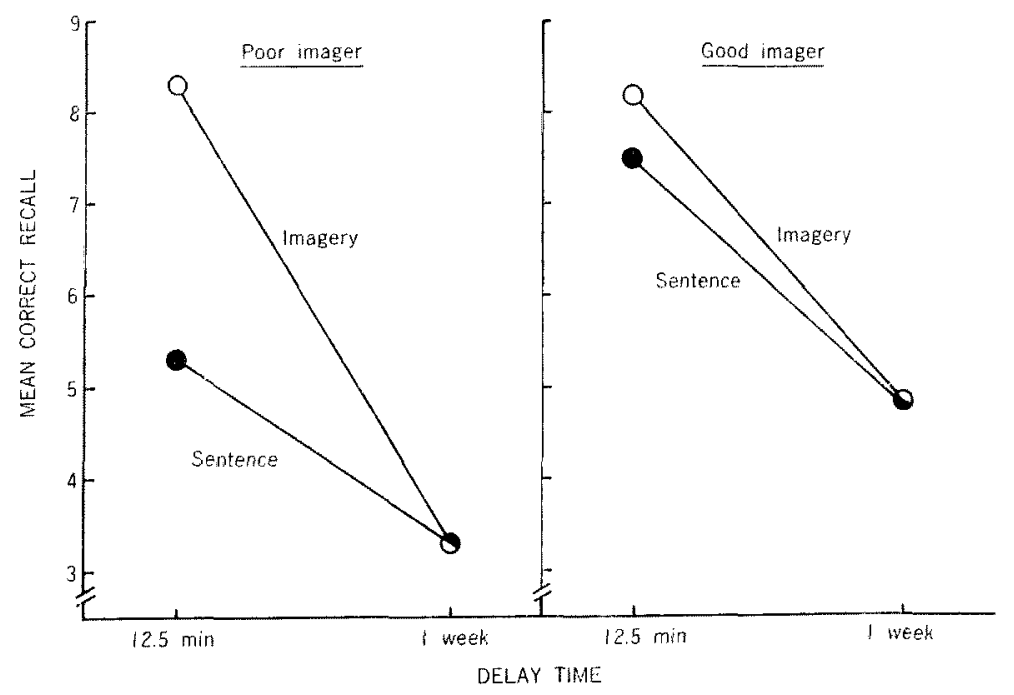

Fìg. 3. Mean number of correct recalls for sentence-generation and imageryformation in good and poor imagers as a function of delay time. 
Table 3

Effects of semantic and perceptual codings in each condition

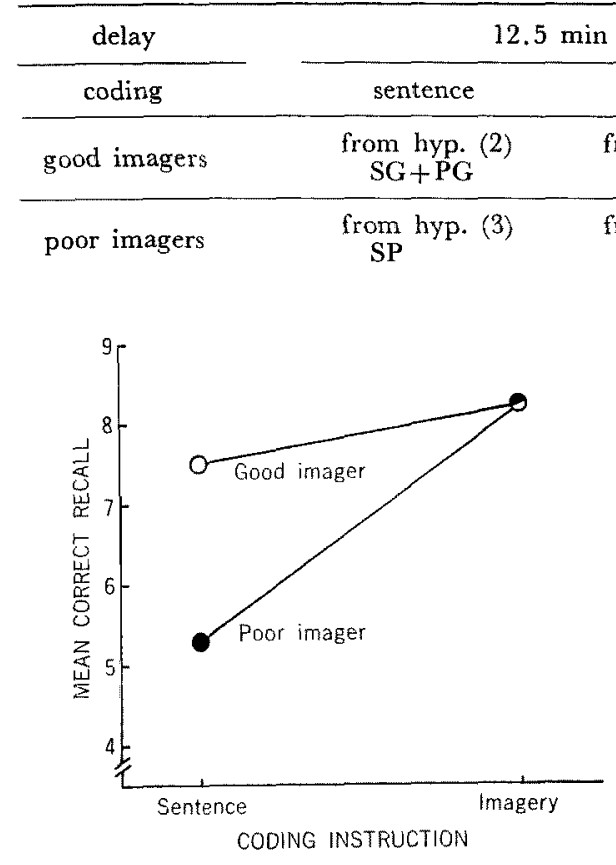

Fig. 4. Mean number of correct recalls of good and poor imagers in group 1 under the condition of 12.5 min delay as a function of coding instruction.

imagers is also equal to it.

5) Imagery ability reflects only the ability of coding input items into the perceptual network, and the effect of semantic coding in good imagers is equal to that in poor imagers.

6) The initial effect of perceptual coding in good imagers is equal to that in poor imagers (from the right panel of Fig. 2).

In the following calculations, the initial effect of semantic coding in good and poor imagers will be given the notation $\mathrm{SG}$ and $\mathrm{SP}$; the effects after time delay, $\mathrm{sG}$ and $s P$; the initial effects of the perceptual coding, $\mathrm{PG}$ and $\mathrm{PP}$; and the effects after the delay, $\mathrm{pG}$ and $\mathrm{pP}$ respectively. Then the hypothesized effects or factors determining the number of recalls in each condition will be as in the Table 3. From hypothesis (5),

$$
\mathrm{SG}=\mathrm{SP}=\mathrm{S}, \quad \mathrm{sG}=\mathrm{sP}=\mathrm{s} .
$$

From hypothesis (6),

$$
\mathrm{PG}=\mathrm{PP}=\mathrm{P} .
$$

Here $\mathrm{pG}$ can be distinguished from other symbols without index, so put

$$
\mathrm{pG}=\mathrm{p},
$$

and hypothesis (4) is expressed as follows, by using new symbols $S, s, P, p$.

$$
\mathrm{S} / \mathrm{s}=(\mathrm{S}+\mathrm{P}) /(\mathrm{s}+\mathrm{p}) \text {. }
$$

Therefore,

$$
\begin{aligned}
\mathrm{S} / \mathrm{s} & -(\mathrm{S}+\mathrm{P}) /(\mathrm{s}+\mathrm{p}) \\
= & (\mathrm{S} * \mathrm{~s}+\mathrm{S} * \mathrm{p}-\mathrm{S} * \mathrm{~s}-\mathrm{s} * \mathrm{P}) / \mathrm{s}(\mathrm{s}+\mathrm{p}) \\
= & (\mathrm{S} * \mathrm{p}-\mathrm{s} * \mathrm{P}) / \mathrm{s}(\mathrm{s}+\mathrm{p}) \\
& =0 . \quad * \text { means multiplying. }
\end{aligned}
$$

Then,

$$
\mathrm{S} * \mathrm{p}=\mathrm{s} * \mathrm{P},
$$

therefore,

$$
\mathrm{S} / \mathrm{s}=\mathrm{P} / \mathrm{p}=(\mathrm{S}+\mathrm{P}) /(\mathrm{s}+\mathrm{p}) .
$$

Estimating the recalls and its rate of decay from the data of poor imagers, the following results were obtained. The symbols for coding effects were substituted as those for estimates of recalls.

$$
\begin{aligned}
& \mathrm{S}=5.3, \quad \mathrm{P}=3.0, \quad \mathrm{~s}=3.3, \\
& \mathrm{~S} / \mathrm{s}=\mathrm{P} / \mathrm{p}=(\mathrm{S}+\mathrm{P}) /(\mathrm{s}+\mathrm{p})=1.6 .
\end{aligned}
$$

By estimating the other numbers of recalls on the basis of these values, Table 4 was obtained. The estimates and the actual observations coincide with each other 
Table 4

Actual recalls and estimates in each condition

\begin{tabular}{|c|c|c|c|c|c|c|}
\hline \multirow{2}{*}{\multicolumn{2}{|c|}{$\begin{array}{l}\text { delay } \\
\text { coding }\end{array}$}} & \multicolumn{2}{|c|}{$12.5 \mathrm{~min}$} & \multicolumn{2}{|c|}{1 week } & \multirow{2}{*}{ mean } \\
\hline & & sentence & imagery & sentence & imagery & \\
\hline \multirow{3}{*}{ good imagers } & factors & $\mathrm{S}+\mathrm{P}$ & $\mathrm{S}+\mathrm{P}$ & $s+p$ & $s+p$ & $(\mathrm{~S}+\mathrm{P}+\mathrm{s}+\mathrm{p}) / 2$ \\
\hline & recalls & 7.5 & 8.2 & 4.8 & 4.9 & 6.3 \\
\hline & estimates & 8.3 & 8.3 & 5.2 & 5.2 & 6.7 \\
\hline \multirow{3}{*}{ poor imagers } & factors & $\mathrm{S}$ & $\mathrm{S}+\mathrm{P}$ & $\mathrm{s}$ & $\mathrm{s}$ & $(2 \mathrm{~S}+\mathrm{P}+2 \mathrm{~s}) / 4$ \\
\hline & recalls & 5.3 & 8.3 & 3.4 & 3.2 & 5.1 \\
\hline & estimates & - & - & - & - & - \\
\hline \multirow{3}{*}{ mean } & factors & $(2 \mathrm{~S}+\mathrm{P}) / 2$ & $\mathrm{~S}+\mathrm{P}$ & $(2 s+p) / 2$ & $(2 s+p) / 2$ & $(4 \mathrm{~S}+3 \mathrm{P}+4 \mathrm{~s}+2 \mathrm{p}) / 8$ \\
\hline & recalls & 6.4 & 8.3 & 4.1 & 4.0 & 5.7 \\
\hline & estimates & 6.8 & 8.3 & 4.2 & 4.2 & 5.9 \\
\hline
\end{tabular}

fairly well except that the estimate of good imagers in sentence instruction in the 12.5 min delay condition is a little greater than the actual observation. This discrepancy may be explained by the possibility that not all good imagers generated imageries in sentence instruction. As for this point, further study will be necessary.

\section{General Discussion}

The important findings resulting from the present study are as follows: Imageryformation is more effective than sentencegeneration in memory of verbal materials, the effects of imagery-formation continues longer in good imagers than in poor imagers, and good imagers are apt to voluntarily use imagery in processing input information. These results will be briefly discussed below.

Begg (1982) considers that imaginal coding is efficient in memory, because "imagery is an effective process for organizing separate pieces of information into new, meaningful units that mediate memory retrieval" (p. 273). If so, however, there seems to be no essential difference in the degree of organization of input items between two coding strategies; one is the sentence-generation in which, for example, "horse" and "grass" are combined by constructing a sentence such as "a horse is eating grass", and the other is the imagery-formation in which those two words are integrated using the imagery that can be described by the above sentence. Therefore, there should be no functional difference in memory process between imagery-formation and sentence-generation, if we try to explain the effects of integrated imagery on memory in terms of the organization by which input items are related with each other. In fact, Anderson and Bower (1973) and Bower (1970) take this standpoint.

Certainly, imagery-formation has the same function of organizing input items as sentence-generation. However, it is difficult to explain the results from Experiment 1 in the present study, which showed that imagery-formation is more effective than sentence-generation, in terms of only organization. In imagery-formation, the subjects may be expected to elaborate information in memory in addition to merely organizing information. For example, if a person trys to construct the imagery "a bird is pecking at a fruit" for " bird" and "fruit", he or she should determine the perceptual attributes of the imagery such as the form of the bird, its marking, the color of the fruit, and so on. However, this elaboration process will not be needed in sentence-generation. Therefore, information in memory can be discrimi- 
nated more sensitively in imagery-formation than in sentence-generation, and the performance in the former becomes higher than in the latter. The finding by Slack (1983), which showed that "the subjects often use imagery to discriminate semantically similar sentences" (p. 631), supports the above argument.

According to the imagery elaboration model (Kieras, 1978), detailed information by imaginal coding is mainly represented in perceptual networks. In Experiment 2 of the present study, it was supposed that imagery differences between good and poor imagers reflect only the difference in ability to encode input information into the perceptual network. Following this supposition and the previous studies which showed that the memory performance of good imagers is higher than that of poor imagers (e.g., Hishitani, 1982, 1985; Mckelvie \& Demers, 1973), it is expected that good imagers construct more elaborative or detailed imagery in the perceptual network than poor imagers. This expectation was not directly confirmed in the present study. However, the following finding seems to support indirectly the above expectation: The rate of decay for the effect of imaginal coding is lower in good imagers than in poor imagers.

In general, imageries "lose their individuality" with time, and "spontaneously change toward typicality" (Reese, 1977 , p. 229), so that the lapse of time lowers the efficiency of imagery in discriminating among various informations in memory. However, the more elaborate the imagery is, the more information the imagery contains in itself, so the rate of decay of the effect of imagery on memory should be lower in detailed than in nondetailed imagery. Therefore, the result from the present study, that the recall of good imagers is more robust in imaginal coding than that of poor imagers over a long time delay, implies that imagery of good imagers is more elaborative than that of poor ones.

There are other studies which showed that good imagers construct more elaborative imagery than poor imagers. For instance, Hishitani (1985) attempted to clarify directly the differences in the structure of imagery between good and poor imagers by analyzing the descriptions reported by the subjects. The results showed that good imagers form imageries having more elaborative structure than poor imagers, and substantiate the expectation mentioned above. Since good imagers can store much available information through imagery-formation as stated above, they may be apt to voluntarily and/or spontaneously construct imagery. However, there have not yet been enough systematic studies concerning the relationship between imagery ability and imagery-use tendency, so further study will be necessary to confirm the above assumption.

\section{References}

Anderson, J. R., \& Bower, G. H. 1973 Human associative memory. Washington, D.C.: Winston.

Begg, I. 1982 Imagery, organization, and discriminative processes. Canadian Journal of Psychology, 36, 273-290.

Bower, G. H. 1970 Imagery as a relational organizer in associative learning. Journal of Verbal Learning and Verbal Behavior, 9, 529-533.

Bower, G.H. 1972 Mental imagery and associative learning. In L. Gregg (Ed.), Cognition in learning and memory. New York: Wiley. Pp. 51-88.

Hishitani, S. 1980 Imagery values for concrete nouns and integrated imagery values for concrete noun pairs and triplets as a unit. THEORIA, 23, 97-117. (College of General Education, Kyushu University) (In Japanese with English summary)

Hishitani, S. 1982 Effects of the relationship between visual imagery ability and task characteristics on memory. Japanese Journal of Educational Psychology, 30, 22-28. (In Japanese with English summary)

Hishitani, S. 1985 Imagery differences and task characteristics in memory. In D. F. Marks \& 
D. G. Russell (Eds.), Imagery 1. Dunedin: Human Performance Associates. Pp. 5-13.

Kieras, D. 1978 Beyond pictures and words: Alternative information-processing models for imagery effects in verbal memory. Psychological Bulletin, 85, 523-554.

Kosslyn, S. M., \& Jolicocur, P. 1980 A theorybased approach to the study of individual differences in mental imagery. In R. E. Snow, P. A. Federico \& W. E. Montague (Eds.), Aptitude, learning, and instiution. Vol. 2. New Jersey: Lawrence Erlbaum Associates. Pp. 139-175.

Mckelvie, S.J., \& Demers, E. G. 1979 Individual differences in reported visual and memory performance. British Journal of Psychology, 70, 51-57.

Marks, D. F, 1973 Visual imagery differences in the recall of pictures. British Joumal of $P_{s y}$ chology, 64, 17-24.

Milgram, N. A. 1967 Verbal context versus visual compound in paired-associate learning by children. Journal of Experimental Child Psychology, 5, 597-603.
Mueller, J.H., \& Jablonski, E. M. 1970 Instructions, noun imagery, and priority in free recall. Psychological Reports, 27, 559-566.

Paivio, A. 1971 Imagery and verbal processes. New York: Holt, Rinehart, Winston.

Reese, H.W. 1965 Imagery in paired-associate learning in children. Journal of Experimental Child Psychology, 2, 290-296.

Reese, H. W. 1977 Toward a cognitive theory of mnemonic imagery. Journal of Mental Imagery, 2, 229-244.

Richardson, A. 1977a The meaning and measurement of memory imagery. British Journal of Psychology, 68, 29-43.

Richardson, A. $1977 \mathrm{~b}$ Verbalizer-visualizer: A cognitive style dimension. Journal of Mental Imagery, 1, 109-126.

Slack, J. M. 1983 Imagery effects and semantic similarity in sentence recognition memory. $\mathrm{Mem}$ ory and Cognition, 11, 631-640.

(Received Jan. 21, 1985; accepted June 29, 1985) 